\title{
Craniofacial-deafness-hand syndrome
}

INSERM

\section{Source}

INSERM. (1999). Orphanet: an online rare disease and orphan drug data base.

Craniofacial-deafness-hand syndrome. ORPHA:1529

Craniofacial-deafness-hand syndrome (CDHS) is an autosomal dominant disorder, described in one family to date, characterized by characteristic facial features (flat facial profile with normal calvarium, hypertelorism, small downslanting palpebral fissures, hypoplastic nose with button tip and slitlike nares, small "pursed" mouth), profound sensorineural deafness, and ulnar deviations and contractures of the hand. CDHS is thought to be an allelic variant of Waardenburg syndrome (see this term) that can be disting uished from the latter by its imaging findings and distinct facial features. 